\title{
Pengaruh Kemampuan dan Motivasi Kerja Terhadap Kinerja Karyawan di Hotel Isola Resort \& Meeting Services
}

\author{
Lu'luwatin Rosdiana Aprilia \\ Akademi Pariwisata NHI \\ luluwatinrosdianaaprilia@gmail.com
}

\begin{abstract}
ASEAN Economic Community $(A E C)$ is a major issue in the world of tourism, especially for the hospitality industry. The quality of human resources becomes essential aspects in order to face the AEC, therefore employee performance is very important to note the suitability those performance low can be influenced by some issues ability and motivation work employees. The aim of this research is to find out how the work ability and motivation give or affect the performance of employees di Hotel Isola. The method used in this research is explanatory survey method. Samples were frontline employees as much as 40 respondents by stratified random sampling. Data were analyzed by by using path analysis with SPSS V.22.0 The results showed that there is influence between the variables of work ability and variable work motivation on employee performance.
\end{abstract}

Keywords - work ability; work motivation; employee performance

Abstrak- Kinerja karyawan sangatlah penting untuk diperhatikan, rendah tidaknya kinerja tersebut dapat dipengaruhi oleh beberapa hal diantaranya kemampuan kerja dan motivasi kerja karyawan. Tujuan Penelitian ini adalah untuk mengetahui bagaimana kemampuan kerja dan motivasi kerja memberikan atau mempengaruhi kinerja karyawan di Hotel Isola. Metode yang digunakan dalam penelitian ini adalah metode survey explanatory. Sampel penelitian ini adalah karyawan frontliner sebanyak 40 orang responden dengan menggunakan stratified random sampling. Teknik analisis data yang digunakan adalah analisis jalur (path analysis). Simpulan penelitian ini menunjukkan bahwa terdapat pengaruh antara variabel kemampuan kerja dan Variabel motivasi kerja terhadap Kinerja karyawan sebesar.

Kata kunci-kemampuan kerja; motivasi kerja; kinerja karyawan

\section{PENDAhUluan}

Dimulai pada tahun 2007, Masyarakat Ekonomi Asean (MEA) 2015 yang dideklarasikan pada sebuah blueprint, 10 negara telah menandatanganinya untuk menjadikan Asia Tenggara menjadi pasar besar dan berpotensi meraup keuntungan serta stabilitas ekonomi di Asia Tenggara. MEA berlangsung sepenuhnya mulai akhir tahun 2015 yaitu pada tanggal 31 Desember 2015. Selain harapan yang bagus dari terbentuknya MEA, tidak terlepas dari beberapa dampak yang akan muncul setelah berlangsungnya MEA diantaranya alur bebas baik itu barang maupun jasa. Bidang yang paling diperhatikan dalam menghadapi MEA di Indonesia adalah pariwisata, karena menjadi lokomotif pembangunan ekonomi, industri yang berkaitan dengan jasa salah satunya adalah industri perhotelan. Tenaga kerja atau yang kita kenal dengan sebutan karyawan merupakan asset yang sangat esensial dalam suatu perusahaan, ilmu MSDM menyebutnya human capital. Industri perhotelan adalah bisnis yang menjual keramahtamahan yang bergantung pada karyawan dengan kinerja yang baik dan optimal.
Permasalahan mengenai kinerja merupakan permasalahan yang rutin dan pasti dihadapi oleh manajemen, maka dari itu perusahaan/organisasi perlu memiliki beberapa strategi dalam menyelesaikannya dengan memperhatikan faktor-faktor yang mempengaruhi kinerja tersebut. T.R Mitchel dalam Sedarmayanti (2001 : 136) menjelaskan bahwa : Performance $=$ ability $\mathrm{x}$ motivation , artinya kinerja seseorang dapat dilihat dari kajian khusus mengenai kemampuan dan motivasi dalam bekerja dimana kemampuan yang dimiliki seseorang dapat meningkatkan kinerjanya didukung dengan motivasi yang mendorongnya untuk bekerja.

Secara teoritis Goleman (1995) menyatakan bahwa kemampuan kerja yang meliputi pengetahuan, ketrampilan dan sikap merupakan determinan penting bagi hasil kerja atau prestasi kerja karyawan. Karyawan melakukan setiap kegiatan atas dasar dorongan yang timbul dari kekuatan dalam diri, kekuatan tersebut selalu disebut dengan motivasi. Motivasi merupakan hasrat di dalam diri seseorang yang menyebabkan orang tersebut melakukan 
tindakan. Motivasi timbul diakibatkan oleh faktor dari dalam dirinya sendiri (faktor intrinsik) dan faktor yang dari luar diri (faktor ekstrinsik).

Berdasarkan pada teori yang digambarkan di atas penulis mengadakan penelitian di Hotel Isola Resort yang merupakan salah satu industri jasa yang menjadi motor kemajuan ekonomi Negara Indonesia terutama di sektor pariwisata wajib meningkatkan kinerja individu karyawannya agar target hotel tercapai dan tepat sasaran karena dengan demikian dapat memberikan dampak positif bagi keterampilan dan kecakapan karyawan yang terus meningkat dan pada akhirnya akan menambah tingkat kefektifan kerja serta keuntungan perusahaan. Terdapat indikasi bahwa kinerja karyawan di Isola Resort belum mencapai hasil yang maksimal sesuai dengan kriteria yang ditentukan oleh perusahaan, Hal ini diperkuat dari hasil wawancara yang dilkukan penulis dengan Human Resources Manager (HRD) bahwa kinerja belum tercapai.

Dalam penelitian ini penulis membatasi pada karyawan Front Liner yang terdiri dari Karyawan Front Office (Kantor Depan Hotel) sebanyak 13 orang, Karyawan Housekeeping (Tata Graha dan Binatu) sebanyak 20 orang dan Food and Beverage (Dapur dan Restoran) sebanyak 12 orang maka jumlah keseluruhan berjumlah 45 orang karyawan, jika dilihat dari hasil penilaian di kategorikan cukup baik, tetapi dari hasil wawancara masih ditemukan keluhan dari tamu yang diakibatkan oleh kinerja karyawan. Pernyataan tersebut juga didukung oleh data rekapitulasi kinerja karyawan di Isola Resort yang dapat dilihat pada tabel berikut ini :

TABEL 1. REKAPITULASI KINERJA KARYAWANHOTEL ISOLA RESORT \& MEETING SERVICES TAHUN 2011-2015

\begin{tabular}{|c|c|c|c|c|c|c|}
\hline \multirow{2}{*}{$\begin{array}{l}\mathrm{N} \\
\mathrm{O}\end{array}$} & \multirow{2}{*}{$\begin{array}{c}\text { Tahu } \\
\mathrm{n}\end{array}$} & \multicolumn{3}{|c|}{ Department/Divisi } & \multirow{2}{*}{$\begin{array}{c}\text { Rata- } \\
\text { rata }\end{array}$} & \multirow{2}{*}{$\underset{\mathrm{ri}}{\text { Katego }}$} \\
\hline & & $\begin{array}{c}\text { Fron } \\
t \\
\text { Offic } \\
e \\
\end{array}$ & $\begin{array}{c}\text { Hous } \\
e \\
\text { keepi } \\
\text { ng }\end{array}$ & $\begin{array}{c}\text { Food } \\
\& \\
\text { Beve } \\
\text { rage }\end{array}$ & & \\
\hline 1 & 2011 & 80,3 & 81,1 & 80,8 & 80,8 & Baik \\
\hline 2 & 2012 & 76,6 & 78,0 & 76,2 & 77,1 & Cukup \\
\hline 3 & 2013 & 78,5 & 77,4 & 77,0 & 77,6 & Cukup \\
\hline 4 & 2014 & 77,7 & 76,2 & 76,6 & 76,6 & Cukup \\
\hline 5 & 2015 & 76,0 & 76,3 & 75,8 & 75,9 & Cukup \\
\hline
\end{tabular}

Berdasarkan tabel 1 dapat kita lihat bahwa tingkat kinerja karyawan semakin tahun semakin menurun hanya saja terjadi sedikit peningkatan antara tahun 2012 dan tahun 2013, akan tetapi setelah itu mengalami lagi penurunan hingga tahun 2015. Dari beberapa item yang menjadi aspek penilaian kinerja selama lima tahun berturut-turut dari tahun 2011-2015 nilai terendah adalah rata-rata berada pada aspek atau item assosiation with dept. head \& Spv yang artinya hubungan dengan atasan kurang baik yang terindikasi karena ada hal atau sesuatu yang menajdi pemicu keadaan tersebut.

Maka diduga indikasi rendahnya kinerja tersebut karena belum sepenuhnya didukung oleh kemampuan kerja dan motivasi yang tinggi sehingga hasil kerja yang dicapai belum optimal. Penulis menduga permasalahan tersebut diakibatkan tidak optimalnya kemampuan kerja karyawan di hotel tersebut yang kemungkinan karena terjadi adanya perampingan karyawan (downsizing) di bagian frontliner, juga rendahnya motivasi karyawan dalam melaksankan pelayanan kepada tamu karena dampak downsizing yang dilakukan yang menimbulkan keresahan, kecemasan atau yang disebut dengan stress kerja pada karyawannya sendiri.

Berdasarkan uraian latar belakang yang telah di dikemukakan, maka tujuan pelaksanaan penelitian ini adalah: ingin mengetahui pengaruh kemampuan dan motivasi terhadap kinerja karyawan di Hotel Isola Resort \& Meeting Services.

\section{KAJIAN PUSTAKA}

\section{A. Kemampuan Kerja}

Menurut Sinungan (2003:67) : Istilah kemampuan didefinisikan dalam arti apa yang diharapkan di tempat kerja, dan merujuk pada pengetahuan, keahlian, dan sikap yang dalam penerapannya harus konsisten dan sesuai standar kinerja yang dipersyaratkan dalam pekerjaan. Fitz dalam Swasto (2000:80) mengemukakan bahwa indikator kemampuan kerja dapat diklasifikasikan sebagai berikut :

1. Kemampuan pengetahuan, adalah pemahaman secara luas mencakup segala hal yang pernah diketahui yang berkaitan dengan tugas-tugas individu dalam organisasi.

2. Kemampuan keterampilan merupakan kemampuan psikomotorik dan teknik pelaksanaan kerja tertentu yang berkaitan dengan tugas individu dalam organisasi.

3. Kemampuan sikap merupakan kemampuan yang mempunyai pengaruh tertentu terhadap tanggapan seseorang kepada orang lain, obyek dan situasi yang berhubungan dengan orang tersebut.

\section{B. Motivasi Kerja}

Motivasi berdasarkan Teori Herzberg adalah "sikap seseorang terhadap pekerjaannya yang 
mengarah pada kepuasan kerja" (Luthans, 2001 : 160). Jenis motivasi itu ada dua, yaitu :

1. Motivasi instrinsik atau yang timbul dari diri individu tersebut disebut dengan faktor pendorong

2. Motivasi ekstrinsik atau dari luar diri individu seseorang dikenal dengan teori hygiene factor

\section{Kinerja}

Kinerja pada dasarnya adalah apa yang dilakukan atau tidak dilakukan pegawai (Mathis dan Jackson, 2006:65). Indicator pengukuran kinerja dengan ungkapan "The most critical performance criteria vary from job to job, but the employee performance measures common to most jobs include the following":

\section{Quantity of output}

2. Quality of output

3. Timeliness of output

4. Presence at work

\section{Ability to Teamwor}

D. Penelitian terdahulu

\begin{tabular}{|c|c|c|c|c|}
\hline $\begin{array}{l}\mathrm{N} \\
\mathrm{O}\end{array}$ & Peneliti & $\begin{array}{c}\text { Tahu } \\
\mathrm{n}\end{array}$ & $\begin{array}{c}\text { Variabel } \\
\text { dan Objek }\end{array}$ & Temuan \\
\hline 1 & $\begin{array}{c}\text { Zahra } \\
\text { Idrees, } \\
\text { Xia } \\
\text { Xinpin } \\
\text { g, } \\
\text { Khura } \\
\text { m } \\
\text { Shafi, } \\
\text { Liu } \\
\text { Hua, } \\
\text { Amna } \\
\text { Nazeer }\end{array}$ & 2015 & $\begin{array}{c}\text { Effect of } \\
\text { Salary, } \\
\text { Training } \\
\text { and } \\
\text { Motivation } \\
\text { on Job } \\
\text { Performanc } \\
\text { e of } \\
\text { Employees }\end{array}$ & $\begin{array}{l}\text { Gaji, } \\
\text { Kemampua } \\
\mathrm{n} \text { dan } \\
\text { Motivasi } \\
\text { memiliki } \\
\text { hubungan } \\
\text { positif } \\
\text { dengan } \\
\text { kinerja. } \\
\text { Penelitian } \\
\text { ini akan } \\
\text { membimbin } \\
\text { g top } \\
\text { manajer } \\
\text { untuk } \\
\text { memahami } \\
\text { dengan baik } \\
\text { factor apa } \\
\text { saja yang } \\
\text { dapat } \\
\text { meningkatk } \\
\text { an kinerja } \\
\text { karyawan } \\
\text { sehingga } \\
\text { produktivita } \\
\text { s tinggi. }\end{array}$ \\
\hline 2 & $\begin{array}{l}\text { Dedy } \\
\text { Suryani }\end{array}$ & 2013 & $\begin{array}{c}\text { Pengaruh } \\
\text { Kemampua } \\
\text { n Kerja } \\
\text { (Pengetahua } \\
\text { n, } \\
\text { Keterampila } \\
\text { n dan Sikap) } \\
\text { Karyawan } \\
\text { terhadap } \\
\text { Prestasi } \\
\text { Kerja }\end{array}$ & $\begin{array}{l}\text { Hasil } \\
\text { penelitian } \\
\text { menyebutka } \\
\mathrm{n} \quad \text { bahwa } \\
\text { terdapat } \\
\text { pengaruh } \\
\text { kemampuan } \\
\text { kerja } \\
\text { karyawan } \\
\text { yang } \\
\text { meliputi }\end{array}$ \\
\hline
\end{tabular}

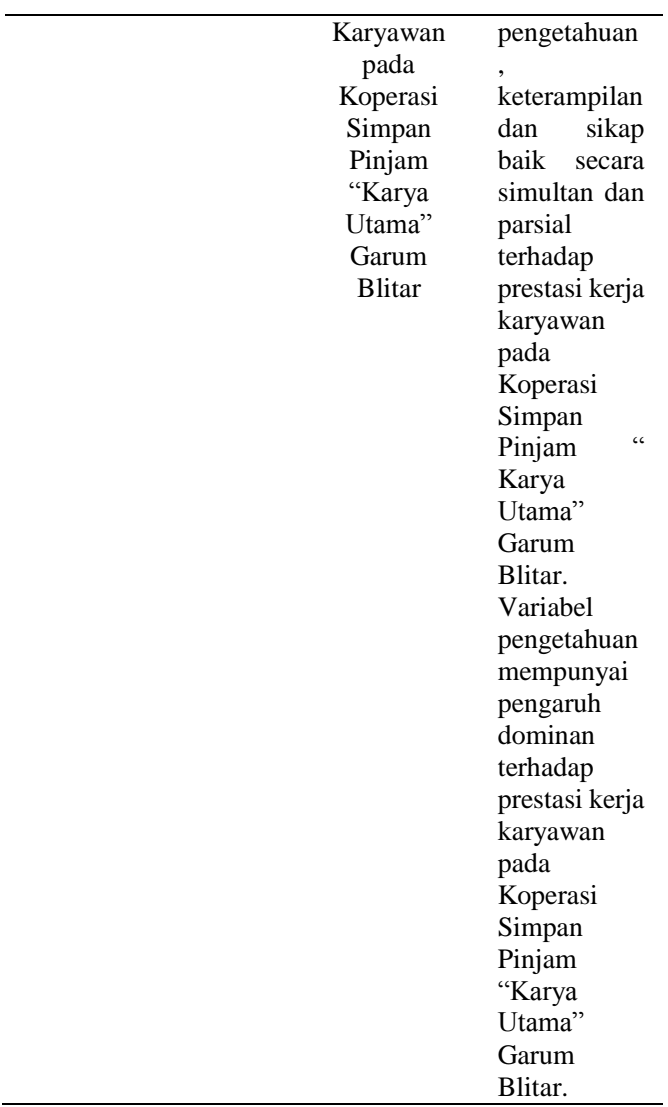

\section{E. Hipotesis}

Hubungan dalam penelitian ini digambarkan dalam hipotesis yang penulis rumuskan dalam penelitian ini yaitu :

\section{Hipotesis 1}

Terdapat pengaruh yang positif dan signifikan dari kemampuan kerja terhadap kinerja karyawan di Hotel Isola Resort \& Meeting Services

\section{Hipotesis 2}

Terdapat pengaruh yang positif dan signifikan dari motivasi kerja terhadap kinerja karyawan di Hotel Isola Resort \& Meeting Services

\section{Hipotesis 3}

Terdapat pengaruh yang positif dan signifikan antara kemampuan dan motivasi kerja terhadap kinerja karyawan di Hotel Isola Resort \& Meeting Services.

Hipotesis ataupun asumsi penelitian dapat disampaikan sesuai kebutuhan.

\section{Metode Penelitian}

Penelitian ini merupakan penelitian kuantitatif, dengan jenis penelitiannya adalah survey (explanatory) dan menggunakan metode 
deskriptif analitik. Metode yang mengumpulkan data melalui pengisian angket maupun wawancara dengan analisis data yang digunakan adalah analisis jalur (path analysis). Pengaruh langsung dari variabel bebas X1 yaitu kemampuan kerja, dan $\mathrm{X} 2$ yaitu motivasi kerja terhadap variabel (Y) yaitu kinerja karyawan, dengan desain penelitiannya dapat digambarkan sebagai berikut:

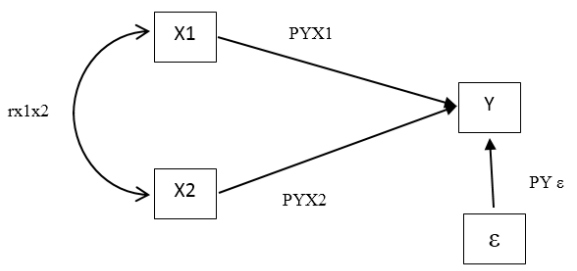

Sumber : Riduwan, 2014 : 290

GAMBAR 1 Diagram JaLUR STRUKTUR HIPOTESIS

Keterangan:

$\mathrm{X} 1 \quad$ : kemampuan kerja

$\mathrm{X} 2 \quad$ : motivasi kerja

Y : kinerja karyawan

$\varepsilon \quad:$ : Epsilon (variabel lain)

rx1x2 : parameter structural, menunjukan hubungan korelasi antara variable $\mathrm{x} 1$ dan $\mathrm{x} 2$

PYX1 : besarnya pengaruh $\mathrm{X} 1$ terhadap $\mathrm{Y}$

PYX2 : besarnya pengaruh $\mathrm{X} 2$ terhadap $\mathrm{Y}$

$\mathrm{PY} \varepsilon \quad$ : pengaruh variable lain terhadap $\mathrm{Y}$

Dalam penelitian ini, jumlah populasi sebanyak 45 orang karyawan frontliner Hotel Isola Resort dimasukkan ke dalam rumus yang dianjurkan oleh Isaac \& Michael (1981) yang didapatkan hasil sejumlah 40 orang. Penelitian menggunakan sampel probabilitas, karena penulis menganggap semua populasi memiliki kesempatan yang sama untuk dipilih. tekniknya menggunakan stratifies random sampling yaitu mengambil sampel secara acak dan berstrata.

Setelah diketahui jumlah sampel (responden) yang diambil dari karyawan front liner $\mathrm{H}$ otel Isola Resort masing-masing departemen, maka responden ditentukan secara random pada saat penelitian sesuai dengan jumlah sampel pada setiap departemen frontliner Isola Resort, seperti terlihat pada tabel berikut ini :

TABEL 3. POPULASI DAN SAMPEL PADA TIAP DEPARTEMEN

\begin{tabular}{ccc}
\hline Departemen & Populasi & Sampel \\
\hline Front Office & 13 & 12 \\
\hline Housekeeping & 20 & 18 \\
\hline Food \& Beverage & 12 & 10 \\
\hline Jumlah & 45 & 40
\end{tabular}

Dalam penelitian ini terdapat dua jenis sumber data, yaitu sumber primer dan sumber sekunder. Sumber primer ialah data yang langsung memberikan informasinya kepada penulis sedangkan sumber sekunder ialah sumber data yang tidak langsung memberikan informasinya, misalnya lewat dokumen dan lainnya, yaitu : 1) Profil perusahaan, struktur organisasi, visi misi; 2) Operasional kegiatan perusahaan; 3) Tanggapan karyawan terhadap kemampuan dan motivasi kerja yang terjadi selama bekerja di Isola resort; 4) Tanggapan Karyawan terhadap kinerja di Isola resort; dan 5) Kinerja pada Isola Resort. Data-data tersebut dikumpulkan dengan menggunakan kuisioner dan wawancara.

\section{Hasil PENELITIAN DAN PEMBAHASAN}

Hotel Isola Resort merupakan sarana pendidikan, pusat kemampuan atau dengan kata lain Hotel Isola Resort dimaksudkan berfungsi sebagai sarana Kemampuan Kerja kewiraswastaan, pengembangan kemampuan dan kegiatan studi-studi di bidang perhotelan dan pariwisata. Namun untuk terus mengembangjan Hotel Isola, maka dibuatlah hotel ini sebagai usaha yang komersial.

Gambaran Karakteristik responden dilihat dari beberapa aspek, yaitu : 1) jenis kelamin : 55\% Laki-laki dan $45 \%$ perempuan; 2) Usia : $80 \%$ berusia $16-25$ tahun, $12,5 \%$ berusia $26-35$ tahun, dan $7,5 \%$ berusia 36-45 tahun; 3) Pendidikan terakhir : $92,5 \%$ lulusan SMA/SMK dan 7,5\% lulusan diploma; 4) Masa kerja : $57,5 \%$ kurang dari 2 tahun, 47,5\% bekerja diantara 2-5 tahun, dan 2,5\% bekerja lebih dari 5 tahun; dan 5) Status perkawinan : sebagian besar $82,5 \%$ belum menikah dan selebihnya $12,5 \%$ sudah menikah.

Rekapitulasi hasil dari persepsi responden mengenai variabel kemampuan kerja, yang dapat dilihat pada tabel berikut ini :

Tabel 4. Rekapitulasi PeRSEPSi ResPonden Mengenai KEMAMPUAN KERJA

\begin{tabular}{ccc}
\hline No & Dimensi & Nilai \\
\hline 1 & Keterampilan & 661 \\
\hline 2 & Sikap & 789 \\
\hline 3 & Pengetahuan & 651 \\
\hline & Jumlah & 2101 \\
\hline & Persentase & $80.8 \%$ \\
\hline \multicolumn{2}{|c}{ Sumber $:$ Hasil Pengolahan Data (2016) }
\end{tabular}

Tabel 3 tersebut adalah gambaran yang berkaitan dengan Persepsi responden mengenai variabel kemampuan kerja secara keseluruhan. Dari hasil pengolahan data yang disajikan, dapat kita lihat bahwa nilai keseluruhan untuk kemampuan kerja adalah 2101. Jumlah tersebut dimasukkan ke dalam garis kontinum, berikut ini : 


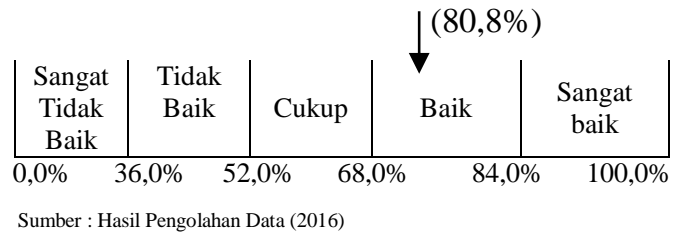

GAMBAR 2. GARIS KONTINUM KEMAMPUAN KERJA

Secara sempurna, nilai yang diharapkan dari 13 pertanyaan ialah 2600. Dari pengolahan data di atas diperoleh nilai 2101 atau $80,8 \%$ dari nilai sempurna yaitu 2600. Dengan demikian Kemampuan kerja berada pada kategori baik.

Rekapitulasi hasil dari persepsi responden mengenai variabel kemampuan kerja, yang dapat dilihat pada tabel berikut ini :

TABel 5. REKAPITUlasi PERSEPSI RESPONDEN MENGENAI MOTIVASI KERJA

\begin{tabular}{ccc}
\hline No & Dimensi & Nilai \\
\hline 1 & faktor Pendorong & 1080 \\
\hline 2 & Faktor Hygiene & 1727 \\
\hline & Jumlah & 2807 \\
\hline & Persentase & $78.0 \%$ \\
\hline
\end{tabular}

Sumber : Hasil Pengolahan Data (2016)

Tabel 4 tersebut adalah gambaran yang berkaitan dengan Persepsi responden mengenai variabel motivasi kerja secara keseluruhan. Dari hasil pengolahan data yang disajikan, dapat kita lihat bahwa nilai keseluruhan untuk Motivasi kerja adalah 2807. Jumlah tersebut dimasukkan ke dalam garis kontinum, berikut ini :

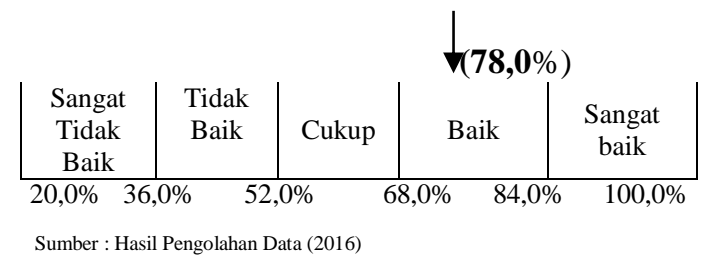

GAmbar 3. Garis KontinUm MOTIVASI KeRJA

Gambaran yang berkaitan dengan Persepsi responden mengenai variabel kinerja karyawan secara keseluruhan. Dari hasil pengolahan data yang disajikan, dapat kita lihat bahwa nilai keseluruhan untuk Motivasi kerja adalah 1100. Jumlah tersebut dimasukkan ke dalam garis kontinum, berikut ini :

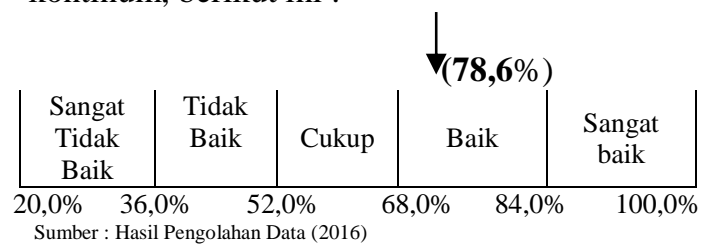

GAMBAR 4. GARIS KONTINUM KINERJA KARYAWAN
Secara sempurna, nilai yang diharapkan dari 7 pertanyaan yang dijawab responden ialah 1400. Dari pengolahan data di atas diperoleh nilai 1100 atau 78,6\% dari nilai sempurna yaitu 1400. Dengan demikian kinerja karyawan berada pada kategori baik. Besaran koefisien jalur dalam penelitian ini, semuanya dapat dilihat pada tabel di bawah ini :

\begin{tabular}{cccc} 
TABEL 6. BESARAN KoEFISIEN JALUR \\
\hline Variabel & $\begin{array}{c}\text { Koefisien } \\
\text { Jalur }\end{array}$ & $\begin{array}{c}\text { Pengaruh } \\
\text { Secara } \\
\text { Bersamaan }\end{array}$ & $\begin{array}{c}\text { Pengaruh } \\
\text { Residu }\end{array}$ \\
\hline Kemampuan & $\mathrm{P}_{\mathrm{yx} 1}=$ & 0,632 & 0,368 \\
Kerja $\left(\mathrm{X}_{1}\right)$ & 0,667 & & \\
\hline Motivasi & $\mathrm{P}_{\mathrm{yx} 2}=$ & & \\
Kerja $\left(\mathrm{X}_{2}\right)$ & 0,240 & & \\
Sumber : Hasil Pengolahan Data $(2016)$ & &
\end{tabular}

Berdasarkan tabel di atas, maka diperoleh hasil persamaan jalur sebagai berikut :

$$
Y=0,667 X 1+0,240 \times 2+0,368 \varepsilon 1
$$

Yang berarti : Kinerja $=0,667$ Kemampuan Kerja + 0,240 Motivasi Kerja + 0,368 faktor lain. Pada persamaan model struktural, nilai koefisien jalur dari variabel eksogen terhadap variabel endogen hanya satu kemungkinannya yaitu bertanda positif. Nilai koefisien jalur yang positif artinya variabel eksogen akan meningkatkan variabel endogen, sedangkan jika ada nilai koefisien jalur yang negatif artinya variabel eksogen akan menurunkan tingkat variabel endogen. Pada hasil analisis jalur di atas, semua variabel (X) bertanda positif, artinya variabel kemampuan kerja dan motivasi kerja akan memberikan pengaruh positif terhadap kinerja karyawan (Y). Secara jelas mengenai diagram jalur analisis hubungan antara X1,X2 dan $\mathrm{Y}$ tertuang pada gambar 4.9 berikut ini :

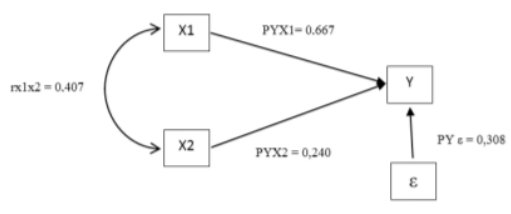

(Sumber : Hasil Pengolahan Data, 2016)

GAMBAR 5 DiAgRAM JALUR HUBUNGAN KAUSAL EMPIRIS X1 DAN X2 TERHADAP Y

Untuk pengujian hipotesis dilakukan uji secara simultan dengan uji $\mathrm{F}$ dan uji secara parsial dengan uji t. Hasil perolehan pengujian secara simutan penelitian ini tertuang pada tabel 7 dan digambarkan pada gambar di bawah ini : 
Tabel 7. Pengujian Secara Simultan

\begin{tabular}{|c|c|c|c|c|c|}
\hline $\begin{array}{l}\text { Hipote } \\
\text { sis } \\
\text { Alterna } \\
\text { tif } \\
\end{array}$ & $\begin{array}{c}\text { F } \\
\text { hitu } \\
\text { ng }\end{array}$ & $\mathrm{db}$ & $\begin{array}{c}\mathrm{F} \\
\text { tabe } \\
1\end{array}$ & $\begin{array}{c}\text { Keput } \\
\text { usan }\end{array}$ & $\begin{array}{c}\text { Kesimpul } \\
\text { an }\end{array}$ \\
\hline $\begin{array}{c}\mathrm{X}_{1 \text { dan }} \\
\mathrm{X}_{2} \\
\text { secara } \\
\text { simulta } \\
\mathrm{n}\end{array}$ & $\begin{array}{c}31,7 \\
98\end{array}$ & $\begin{array}{l}\mathrm{db}_{1} \\
=2\end{array}$ & $\begin{array}{l}3,2 \\
52\end{array}$ & $\begin{array}{c}\mathrm{H}_{0} \\
\text { ditolak }\end{array}$ & $\begin{array}{c}\text { Signifika } \\
\mathrm{n}\end{array}$ \\
\hline $\begin{array}{c}\text { berpen } \\
\text { garuh } \\
\text { terhada } \\
\text { p Y }\end{array}$ & & $\begin{array}{c}\mathrm{db}_{2} \\
= \\
37\end{array}$ & & & \\
\hline
\end{tabular}

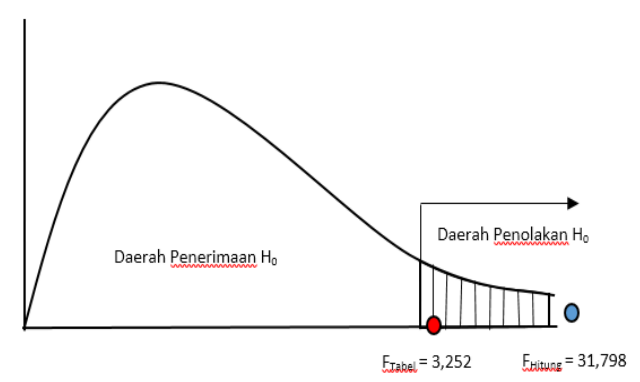

Sumber : Hasil Pengolahan Data (2016)

GAmbar 6 Pengujian SECARA Simultan

TABEL 8. PENGUJIAN PARSIAL

\begin{tabular}{cccccc}
\hline $\begin{array}{c}\text { Hipot } \\
\text { esis }\end{array}$ & $\begin{array}{c}\mathrm{t} \\
\text { hitung }\end{array}$ & $\begin{array}{c}\mathrm{D} \\
\mathrm{b}\end{array}$ & $\begin{array}{c}\mathrm{t} \\
\text { tabel }\end{array}$ & $\begin{array}{c}\text { Keputus } \\
\text { an }\end{array}$ & $\begin{array}{c}\text { Kesimpu } \\
\text { lan }\end{array}$ \\
\hline $\mathbf{P}_{\mathbf{y x 1}}$ & 6,109 & 37 & 2,02 & $\mathrm{H}_{0}$ & Signifika \\
$\mathbf{= 0}$ & & & 6 & ditolak & $\mathrm{n}$ \\
$\mathbf{P}_{\mathbf{y x 2}}$ & 2,196 & 37 & 2,02 & $\begin{array}{c}\mathrm{H}_{0} \\
\text { ditolak }\end{array}$ & $\begin{array}{c}\text { Signifika } \\
\mathrm{n}\end{array}$ \\
$\mathbf{= 0}$ & & & 6 & &
\end{tabular}

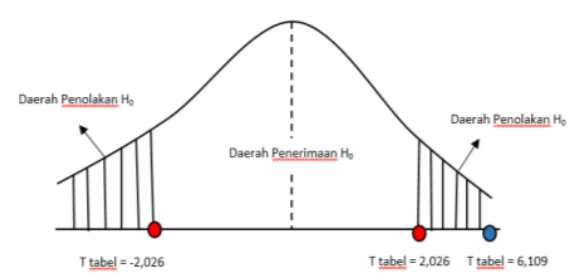

Sumber : Hasil Pengolahan Data (2016)

Gambar 7 Pengujian SeCara Parsial X1

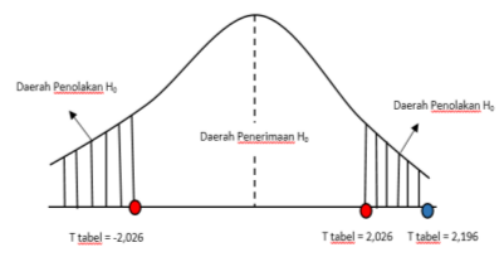

Sumber : Hasil Pengolahan Data (2016)

GAMbar 8 PEngujIan SECARA PARSIAL X2

Dari tabel 7, gambar 7 dan gambar 8 di atas dapat kita ketahui bahwa nilai thitung untuk variabel Kemampuan Kerja (X1) ternyata lebih besar nilainya dari nilai ttabel, maka dapat dipastikan variabel Kemampuan Kerja (X1) secara parsial memberikan pengaruh yang positif dan signifikan terhadap Kinerja Karyawan (Y). Dan nilai thitung untuk variabel Motivasi Kerja (X2) lebih besar dari nilai ttabel, yang artinya variabel Motivasi Kerja (X2) secara parsial memberikan pengaruh yang positif dan signifikan terhadap Kinerja Karyawan (Y) artinya keduanya tidak perlu diperbaiki dengan metode trimming. Untuk melihat pengaruh langsung dan tidak langsung variabel kemampuan kerja terhadap variabel kinerja karyawan adalah sebagai berikut ini :

Tabel 9. Pengaruh Langsung Dan Tidak Langsung KEMAMPUAN KeRJA TERHADAP KINERJA KaRYAWAN

\begin{tabular}{ccc}
\hline \multicolumn{2}{c}{ Pengaruh langsung dan tidak langsung } & $\begin{array}{c}\text { Besar } \\
\text { Kontribusi }\end{array}$ \\
\hline $\mathrm{X}_{1}$ langsung & $\operatorname{pyx}_{1} \mathrm{pyx}_{1}$ & $44,46 \%$ \\
\hline $\mathrm{X}_{1}$ melalui $\mathrm{X} 2$ & $\mathrm{pyx}_{1} \mathrm{rx}_{1} \mathrm{x}_{2} \mathrm{pyx}_{2}$ & $6,51 \%$ \\
\hline \multicolumn{2}{c}{ Total pengaruh $\mathrm{X}_{1}$ terhadap $\mathrm{Y}$} & $50,97 \%$ \\
\hline \multicolumn{2}{l}{ Sumber : Hasil Pengolahan Data (2016) }
\end{tabular}

Dari tabel di atas dapat kita ketahui bahwa total pengaruh yang diberikan variabel Kemampuan Kerja (X1) terhadap variabel Kinerja karyawan (Y) adalah sebesar 50,97\%. Selanjutnya untuk melihat pengaruh langsung dan tidak langsung variabel kemampuan kerja terhadap variabel kinerja karyawan dapat dilihat pada tabel berikut ini :

TABel 10. Pengaruh Langsung Dan TidaK Langsung MOTIVASI KeRJA TERHADAP KINERJA KARYAWAN

\begin{tabular}{ccc}
\hline \multicolumn{2}{c}{$\begin{array}{c}\text { Pengaruh langsung dan tidak } \\
\text { langsung }\end{array}$} & $\begin{array}{c}\text { Besar } \\
\text { Kontribusi }\end{array}$ \\
\hline X2 langsung & pyx2pyx2 & $5,75 \%$ \\
\hline X2 melalui & pyx2rx2x1pyx & $6,51 \%$ \\
X1 & 1 & \\
\hline \multicolumn{2}{c}{ Total pengaruh X2 terhadap Y } & $12,25 \%$
\end{tabular}

Sumber : Hasil Pengolahan Data (2016)

Dari tabel di atas dapat kita ketahui bahwa total pengaruh yang diberikan variabel Motivasi Kerja (X2) terhadap variabel Kinerja karyawan (Y) adalah sebesar 12,25\%. Sebenarnya, permasalahan mengenai kemampuan kerja dan motivasi kerja adalah bukan sesuatu hal yang asing lagi bagi organisasi, karena dua permasalahan tersebut dapat kapan saja terjadi di suatu organisasi bidang apapun, tak ayalnya di hotel kedua elemen ini sangatlah penting untuk di bahas terutama bila dikaitkan dengan prestasi kerja atau disebut kinerja akan menimbulkan akibat yang berbeda-beda baik itu positif maupun negatif.

Hasil penelitian ini didukung oleh jawaban responden yang menyatakan bahwa kemampuan kerja yang terdiri dari keterampilan, pengetahuan dan sikap berada pada kategori dan kriteria baik, dengan artian menunjukkan bahwa 
karyawan merasa mampu menjalankan pekerjaannya. Relevan dengan penelitian yang dilakukan oleh Sidik Priadana dan Iwan Ruswandi (2013) dengan hasil penelitian yang menunjukkan bahwa kemampuan pegawai berada dalam kategori cukup baik, motivasi kerja berada pada kategori baik, dan kinerja berada pada kategori baik.

Pengaruh kemampuan terhadap kepuasan kerja sebesar 0,154, pengaruh motivasi terhadap kepuasan sebesar 0,629, secara bersama-sama pengaruhnya sebesar 0,783 dan sisanya 0,217 oleh faktor lain serta implikasi dari kepuasan kerja terhadap kinerja adalah sebesar 0,699 dan sisanya 0,301 oleh faktor lain. Sedangkan untuk jawaban responden mengenai motivasi kerja rasanya masih kurang terasa adanya motif dan inisiatif yang timbul dari diri masing-masing individu karyawan karena walaupun berada pada kategori baik tapi jauh di bawah variabel kemampuan kerja.

Dalam penelitian ini, ternyata banyak responden yang menjawab bahwa mereka merasa tidak diperhatikan oleh atasan sehingga hasil yang ditampilkan nilainya lebih sedikit daripada kemampuan kerja. Hasil penelitian di Hotel Isola Resort ini karena faktor-faktor lain yang muncul mempengaruhi turunnya motivasi karyawan bisa timbul karena diri individu karyawan tersebut ataupun dari lingkungan sekitar karyawan tersebut. Kondisi demikian diperkuat oleh penelitian terdahulu yang dilakukan oleh Dimas Rizky Akbar (2014) yang dalam penelitiannya diperoleh temuan penelitian mengenai motivasi kerja bahwa tidak ada bukti yang kuat adanya pengaruh positif dan signifikan antara motivasi kerja pegawai negeri sipil terhadap peningkatan kinerjanya dengan total pengaruh hanya sebesar $12 \%$. Hasil penelitian ini senada dengan teori yang diambil dari T.R Mitchel dalam Sedarmayanti (2001 : 136) yang menyebutkan bahwa : Performance = ability x motivation, artinya kinerja seseorang dapat dilihat dari kajian khusus mengenai kemampuan dan motivasi dalam bekerja dimana kemampuan yang dimiliki seseorang dapat meningkatkan kinerjanya didukung dengan motivasi yang mendorongnya untuk bekerja.

\section{KESIMPULAN}

Simpulan umum dari penelitian ini yaitu kemampuan dan Motivasi Kerja memberikan pengaruh yang signifikan terhadap kinerja karyawan di hotel Isola Resort \& Meeting Services". Dari simpulan umum tersebut terdapat beberapa simpulan khusus sebagai berikut :

Kemampuan kerja berpengaruh signifikan terhadap kinerja karyawan di Hotel Isola Resort
\& Meeting Services, kemampuan sudah cukup maksimal dilaksankan oleh karyawan yaitu pada posisi baik dilihat dari aspek keterampilan, sikap dan pengetahuan. Jika memperhatikan kedua variabel bebas yaitu X1 (kemampuan kerja) dan X2 (motivasi kerja) dapat disimpulkan bahwa kemampuan kerja memiliki pengaruh tertinggi tehadap kinerja baik secara korelasi maupun regresi dengan kata lain dengan kemampuan kerja yang tinggi dari karyawan maka kinerja akan meningkat;

Motivasi kerja berpengaruh signifikan terhadap kinerja karyawan di Hotel Isola Resort \& Meeting Services, Motivasi kerja pada karyawan di Hotel Isola Resort \& Meeting Services berada pada posisi baik namun lebih rendah nilainya dibandingkan kemampuan kerja yang dimiliki karyawan, memungkinkan untuk ditingkatkan motivasinya, misalnya mendapatkan penilaian yang adil dari supervisor, juga lingkungan kerja, usaha Hotel Isola Resort \& Meeting Services untuk meningkatkan motivasi karyawan dengan mendatangkan motivator yang handal, membentuk organisasi yang sifatnya akan menumbuhkan semangat seperti out bound, gathering, adanya pentas seni dan lain sebagainya untuk menghilangkan kejenuhan akibat masalah-masalah yang terjadi; dan

Secara simultan, masing-masing dari Kemampuan kerja dan Motivasi Kerja memiliki impresi yang substansial terhadap kinerja karyawan di Hotel Isola Resort. Selanjutnya, Kemampuan kerja dan motivasi kerja secara simultan memberikan pengaruh yang cukup tinggi terhadap kinerja karyawan di Hotel Isola Resort, dan selebihnya yang mempengaruhi kinerja adalah faktor lain yang tidak diteliti. Dengan demikian, kemampuan maupun motivasi bersamaan memberikan pengaruh yang positif dan signifikan terhadap kinerja karyawan di Hotel Isola Resort. hal ini didukung oleh hasil olah data penelitian yaitu jumlah pengaruh langsung maupun tidak langsung sebesar 50,97\% (kemampuan kerja) dan sebasar 12,25\% (motivasi kerja) dari kedua total pengaruh langsung maupun tidak langsung teruji bahwa kemampuan kerja paling berpengaruh terhadap kinerja. Tetapi, masih ada beberapa hal yang pada posisi baik yang harus dipertahankan dan yang nilainya lebih kecil perlu diadakan peningkatan, yang sifatnya menyeluruh dan berkelanjutan, kendala dalam mengatasi pengaruh, kemampuan kerja dan motivasi kerja terhadap kinerja karyawan adalah adanya perampingan karyawan yang terjadi di hotel ini dimulai dari tahun 2014 dengan memperhatikan penurunan kinerja karyawan sebesar $2 \%$ begitupun di tahun 2015 yang semakin menurun, berbeda dengan hasil kinerja 
karyawan pada tahun 2013 yang memperoleh hasil kinerja karyawan sebesar $90 \%$ baik ditambah permasalahan banyaknya karyawan yang belum menikah mempengaruhi rendahnya motivasi untuk bekerja dan terakhir adalah kurangnya perhatian dan penghargaan dari atasan yang dirasakan oleh karyawan. Walaupun demikian hasil peneliatian bahwa kinerja karyawan Hotel Isola Resort \& Meeting Services dalam posisi baik.

Berdasarkan kesimpulan yang diperoleh, maka saran yang dapat diberikan adalah sebagai berikut;

Pihak manajemen hotel diharapkan selalu berusaha untuk mempertahankan atas kemampuan dasar yang dimiliki oleh karyawan, dimana selama ini para karyawan memiliki kemampuan kerja yang baik dalam menjalankan aktivitas rutin yang menjadi tangungjawab mereka. Adapun upaya nyata yang dapat dilakukan yaitu dengan memberikan kemampuan-kemampuan terkait dengan aktivitas operasional hotel kepada karyawan sehingga para karyawan mampu meningkatkan keterampilan dalam bekerja dan pada akhirnya mampu meningkatkan prestasi kerjanya;

Mengenai kemampuan kerja yang paling rendah nilainya adalah dimensi sikap. Maka dari itu, disarankan pihak manajemen hotel selalu berusaha untuk memperbaiki sikap kerja para karyawan di hotel yaitu dengan memberlakukan peraturan kerja secara ketat, melalui usaha tersebut maka para karyawan dapat bekerja dengan memaksimalkan potensi yang dimiliki, yaitu dengan penetapan target kualitas, kuantitas dan waktu penyelesaian pekerjaan secara tegas. Serta adanya gairah dan semangat untuk bekerja;

Mengenai motivasi kerja yang paling rendah nilainya adalah dimensi factor pendorong, maka dari itu disarankan agar hotel lebih dapat meningkatkan motivasi karyawan dengan memberikan perhatian penuh dari atasan serta penghargaan dan penilaian yang positif sehingga karyawan merasa apa yang telah dilakukan dihargai dan berguna bagi hotel yang nantinya berdampak positif bagi kemajuan hotel dapat dilakukan melalui berbagai upaya pengembangan karir karyawan dengan mendatangkan motivator yang mempunyai kemampuan untuk membangkitkan semangat baru kepada setiap karyawan dalam pelaksanan pekerjaanya sehingga tercapainya tujuan perusahaan yaitu memberikan pelayanan yang memuaskan kepada para pelanggan;

Pada penelitian selanjutnya sebaiknya dalam meningkatkan kinerja karyawan suatu organisasi untuk penelitian selanjutnya dapat menggunakan variabel lainnya yang relevan karena seiring berkembangnya zaman akan timbul teori-teori dan konsep baru mengenai kinerja karyawan oleh karena itu dengan harapan akan mendapatkan lebih banyak serta menambah cakrawala dan wawasan yang lebih luas lagi tentang bagaimana cara meningkatkan kinerja karyawan dalam sebuah organisasi seperti kompensai, lingkungan kerja, iklim kerja dan lain-lain,. Selain itu, agar penelitian mengenai kinerja karyawan lebih mendalam dan akurat diharapkan peneliti selanjutnya mewawancarai langsung masing-masing karyawan pada suatu organisasi/perusahaan.

\section{DAFTAR RUJUKAN}

Dimas Rizky Akbar. (2014). Pengaruh Kemampuan, Motivasi dan Kepuasan Kerja Terhadap Kinerja Pegawai Negeri Sipil di Lingkungan Kecamatan Tambaksari Surabaya. Jurnal Kebijakan dan Manajemen Publik Universitas Airlangga Surabaya, 2(1), Januari 2014, ISSN 2303 341X

Goleman, Daniel (1995). Emotional Intelligence. Bantam Books, New York Struktur, Proses. (Edisi Terjemahan) Cetakan Ke-4. Jakarta: Erlangga.

Idrees, Zahra, et. al. (2015). Effect of Salary, Training and Motivation on Job Performance of Employees. American Journal of Business, Economics and Management 3(2), 55-58

Luthans, F. (2011). Organizational Behaviour. $12 e d$. New York : McGraw-Hill

Mathis, R.L. \& J.H. Jackson. (2006). Human Resource Management: Manajemen Sumber Daya Manusia. Terjemahan Dian Angelia. Jakarta: Salemba Empat.

Riduwan \& Kuncoro, E.A. (2014). Cara Menggunakan dan Memaknai Path Analysis (Analisis Jalur). Bandung : Alfabeta

Sedarmayanti. (2001). Sumber Daya Manusia dan Produktivitas Kerja. Cetakan Ketiga. Bandung : CV. Mandar Maju

Sidik Priadana \& Iwan Ruswandi. (2013). Pengaruh kemampuan kerja dan motivasi terhadap kepuasan kerja serta implikasinya pada kinerja pegawai dinas pertambangan dan energy provinsi Jawa Barat. Jurnal Ekonomi, Bisnis, Entrepreneurship, 7(2) Oktober 2013 52-63 ISSN 2443-0633 Unpas Bandung

Sinungan, Muchdarsyah. (2003). Produktivitas apa dan Bagaimana. Jakarta: Bumi Aksara 
Suryani, Dedy, (2013), Pengaruh Kemampuan Kerja(Pengetahuan, Keterampilan, Sikap) Karyawan Terhadap Prestasi Kerja Karyawan Pada Koperasi Simpan Pinjam" Karya Utama" Garum Blitar. Skripsi Jurusan Manajemen Fakultas Ekonomi Universitas Islam Negerin Maulana Malik Ibrahim Malang. 
